\title{
DEVELOPMENT OF PROJECT-BASED LEARNING (PBL) IN BLENDED LEARNING MODE FOR THE ACQUISITION OF DIGITAL COMPETENCE
}

\author{
Olga Arranz-García and Vidal Alonso Secades \\ Faculty of Education, Universidad Pontificia de Salamanca, Salamanca, Spain
}

\begin{abstract}
The objective of this research is to know the perception of future teachers of Elementary and Early Childhood Education in Blended Learning mode of the Faculty of Education at the Pontifical University of Salamanca on the use of an innovative methodology as is the Project Based Learning (PBL) for the acquisition of digital competence. In order to do this, we are here presenting a didactic proposal using Project Based Learning (PBL) as a methodological approach, which is framed in the subject of Information and Communication Technologies (ICT) in the field of education. A quantitative methodology has been carried out using the technique of the questionnaire for data collection. For the assessment, the Questionnaire of Effectiveness of the use of methodologies for Active Participation (CEMPA) has been used. This has been divided into 4 dimensions: Specific Skills, General Skills, Systemic and Interpersonal Skills (Carrasco, Donoso, Duarte-Atoche, Hernandez \& Lopez, 2015). The outcomes are highly positive. These results are supported by other results obtained in former investigations which underwent similar research. Likewise, it is shown that the use of this methodology facilitates the acquisition of digital competence, as well as the development of different skills that are addressed with the use of this type of methodology.

In conclusion, it can be established that the PBL has helped students of the Blended Learning mode to obtain a significant learning both, in the Specific skills as in the General and Systemic ones. On the contrary, no significant learning in Interpersonal skills has been obtained. This may be due to the fact that students under the Blended Learning mode have little interaction with the rest of their peers since it takes place mainly through digital channels.
\end{abstract}

\section{KEYWORDS}

Project-Based Learning (PBL), Blended Learning, Information and Communication Technologies (ICTS), Digital Competence

\section{INTRODUCTION}

Today's teaching-learning process, stands out for the huge breakthrough caused by Information and Communication Technologies (ICTS) in the classroom. Likewise, the current educational legislation is determined to creating scenarios that are required for a didactic transformation that will place the student as an active subject in the teaching-learning process (Organic Law 8/2013).

Therefore, the impact of ICT in education requires teachers not only to be trained in the use of technological tools, but also the acquisition of new methodologies by applying innovative pedagogical strategies that promote optimal results, placing the student as a central axis of learning as well as fostering their multiple intelligences.

After reviewing several studies on the use of ICT in education (Area, 2008; Cabero, 2015; Cabero \& Roman, 2006; Marquès, 2012; Salinas, 2008; Bustos \& Gómez, 2018), many are the experts who state that technology itself, doesn't generate changes or improvements in education. An important factor is to analyze the methodology to be applied and the role that the teacher will perform in this teaching-learning process in order to obtain a successful result. The educator becomes a designer of learning spaces, and technology plays a mediating role in the construction of knowledge and social interaction(Cabero, 2015).

In this sense, the educational law also states that one of the basic skills that students must acquire is the Digital Competence (RD 126/2014), but before this really occurs, teachers need to accomplish this objective as well. 
As indicated by García-Valcárcel \& Basilotta (2017), students' motivation for learning through the implementation of projects in a collaborative way using technological tools goes hand in hand with a very positive self-perception of learning achieved.

Therefore, this paper establishes as its main aim the implementation of innovative active methodology of Project-Based Learning (PBL) for the acquisition of digital competence in their five areas of competence: information, communication, content creation, digital security and problem resolution.

Besides the acquisition of digital competence, other skills related to Project Based Learning (PBL) collaborative methodology are developed:

- Systemic skills: drawing conclusions, problem resolution and management.

- Interpersonal skills: which will develop healthy social interactions with others.

\section{METHOD}

\subsection{Participants}

The present study is framed in the subject of Information and Communication Technologies in Education (ICT) within the syllabus in the Degree of Primary Education and also in the Degree of Early Childhood Education, at the Pontifical University of Salamanca. This study has been conducted in 28 students studying exclusively under the Blended Learning mode. The average age is 33.93. This is high because students who access this modality of learning are mainly students who already have a university degree.

\subsection{Instrument}

As for the instrument the Questionnaire of Effectiveness of the use of methodologies for Active Participation (CEMPA) has been used (Carrasco et al., 2015). This questionnaire has been validated in Spanish and consists of 25 items, with a Likert scale type with five levels of responses (1: little, 2: low, 3: moderate, 4: fairly and 5: much). The items are grouped into four different dimensions:

1. Development of Specific Skills (Items 1-5). This dimension values the abilities related to their own Degree. In our case, the acquisition of digital competence in their five areas of competence within the subject of ICT in education has been assessed.

2. Development of General Skills (items 6-13). In this dimension the skills needed for employment and life as a citizen have been assessed, which are of paramount importance for all students regardless of the Degree chosen. In addition, within this dimension, it is important to establish a close link with the development of the Specific Skills, that is to say, with the acquisition of digital competence in its five areas of competences, since items such as problem resolution, the use computers, database management (search for information), verbal and written communication which are framed within the 5 areas mentioned above.

3. Systemic Skills (Items 14-18). These are related to the overall vision and the ability to properly manage the totality of the question posed.

4. Interpersonal Skills (Items 19-25). In this last dimension, the capabilities that allow you to maintain good social relationships with others are assessed.

\subsection{Process}

The didactic proposal presented here is titled "The Saddlebags Digital Competence". The purpose for using the methodology of Project-Based Learning (PBL) is the creation of a personal learning environment (PLE) containing the main ICT resources to be used in the classroom in Early Childhood and Primary Education according to the major selected (Foreign Language, Music, Physical Education, Special Needs Education and Speech Therapist).

The abilities and capabilities targeted in this didactic proposal are:

$\checkmark$ To promote experiences of initiation to information and communication technologies.

$\checkmark$ To know, use and incorporate ICT in teaching-learning activities. 
To develop a professional approach to facilitate decision-making on the use, design and evaluation of educational materials in computer support.

$\checkmark$ To raise awareness in the need for continuous professional development promoted by the daily evolution of ICT.

"The Saddlebags Digital Competence" takes place in three different phases:

1. Phase 1. The stages in this phase are:

- Specify the theme of work. In our case, the search for ICT resources to be used in the classrooms of Early Childhood and Primary Education.

- Teams building. The teams are organized in groups of 4 students per computer and the roles within the teams are assigned.

- To clarify the final outcome for each of the teams.

2. Phase 2. In the 2nd phase the following elements are defined:

- Planning: A work agenda is established as well as all the members' contributions.

- Research: consist of searching, selecting and dealing with existing ICT resources in the web with the use of different technological programs of content curators (Pinterest, Pocket, Digital Whiteboard).

- Analysis and Synthesis: consist of analyzing the information obtained and withdraw it wisely, critically and ethically in order to display it and share it.

3. Finally, in phase 3 the final product is originated:

- Creation of the final content collecting all groups' contributions using the different ICT tools (Symbaloo).

- Exposure of the content elaborated using digital resources (Mindomo).

- Raising a debate among the projects developed by the different groups.

\section{DATA ANALYSIS}

Once this proposal for teaching was applied, the students completed the Questionnaire of Effectiveness of the use of methodologies for Active Participation (CEMPA). In order to analyze the data, the statistical package SPSS 24 was used.

\subsection{Results}

According to the data obtain in the different items, the average of the 4 dimensions established in the questionnaire, has been examined in the first place, as it is shown in Figure 1:

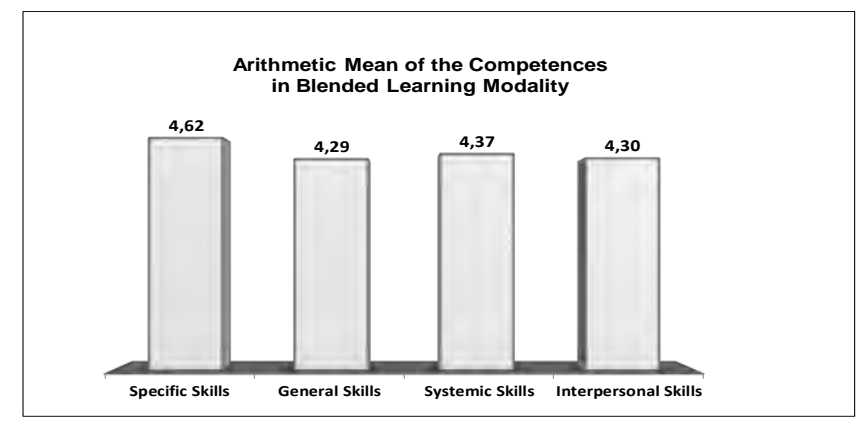

Figure 1. Arithmetic mean of the four dimensions of the questionnaire 
As can be observed from the average values obtained in the 4 dimensions that encompasses the questionnaire, students in Blended Learning modality believe they have acquired the different competences in a very significant level, that is to say, they believe that the use of the innovative methodology of PBL is very appropriate for the acquisition of the digital competence. As for the learning of Specific Skills $(\mathrm{M}=4.62)$, these prevail over the rest of the competences which have a very similar arithmetic mean.

Once the arithmetic averages were observed, a statistical analysis Chi-square to the data obtained in the sampling was carried out. Values resulting from the asymptotic significance level by linking the different competences described in the questionnaire CEMPA are reflected below in Table 1. The values in the table are symmetrical, therefore only values represented in the middle of the table are shown.

Table 1. Representation of the values of the asymptotic significance using Chi-square test for the relationship between the different skills

\begin{tabular}{ccccc}
\hline & Specific Skills & General Skills & Systemic Skills & Interpersonal skills \\
\hline Specific Skills & 0.018 & 0.000 & 0.063 \\
\hline General Skills & & 0.045 & 0.119 \\
\hline Systemic Skills & & & 0.476 \\
\hline Interpersonal Skills & & & \\
\hline
\end{tabular}

Since the $95 \%$ in the confidence coefficient was used, the significance level obtained is $5 \%(0.05)$. Therefore, taking into account the values of the asymptotic significance represented in Table 1 , it can be considered that:

$\checkmark$ The asymptotic significance (bilateral) of the Specific skills with the General skills, is $0.018<0.05$, and with the Systemic skills is $0.000<0.05$, therefore, in both cases, we do consider that there is a relationship between these competences. However, the asymptotic significance (bilateral) of the Specific skills with the Interpersonal is not significant $(0.063>0.05)$ therefore, it cannot be stated that there is relationship between the two skills.

$\checkmark$ The asymptotic significance (bilateral) of the General skills with the Systemic skills is $0.045<0.05$, therefore, it can be ratified that there is a relationship between these competences. However, as in the case mentioned above, there is no significant relationship with Interpersonal skills $(0.119>0.05)$.

$\checkmark$ As for the Systemic skills, we haven't found any variation with the Interpersonal skills $(0.476>$ 0.005). In this way, it cannot be said that there is any relationship.

$\checkmark$ Finally, the Interpersonal skills don't have relationship with any of the rest of the competences. Its asymptotic significance is greater than 0.05 , in all the values.

\section{CONCLUSION}

After applying this didactic proposal, students in the Blended Learning modality believe they have acquired a very high level in the different skills described in this study. The Specific skills stand out the rest of skills. With an almost identical value but with a lower score, the General skills as well as the Systemic skills emerge. Interpersonal skills, though showing a fairly high rating, are the ones that get the lowest values if we compare them with the rest of competences.

Statistically significant relationships between the Specific skills and the General skills $(\mathrm{p}<0.05)$ have been found, as well as between the Specific skills and the Systemic $(p<0.05)$, as happens between the General and the Systemic $(p<0.05)$. However, no statistically significant relationship has been found between the Interpersonal skills and the other skills.

In conclusion, it can be established that the PBL has helped students of the Blended Learning mode to obtain a significant learning both, in the Specific skills as in the General and Systemic skills. Nevertheless, no significant learning has been obtained in the Interpersonal skills, as Prendes, Castañeda \& Gutiérrez (2010), and Fernandez-Cabezas (2017) show in their studies, where it is stated that the greatest students' shortcomings are those related to collaboration, leadership and management of the information in teamwork. As stated by Hernandez (2016) there are other studies where it is confirmed that this type of 
methodologies requires an effort in planning and monitoring in order to guarantee the communication or collaboration among students.

Following Thomas (2000), the results obtained show, not only the importance of students' motivation for accomplishing significant learning, but also for the need of a good planning and organization of the tasks in the projects. Therefore, it is very important within this methodological context, to find a solution in order to obtain greater Interpersonal skills for the students in the Blended Learning modality where group interactions occur primarily through digital channels.

\section{REFERENCES}

Area, M. (2008). ICT pedagogical innovation and development of information and digital competencies. Journal of Research in school, 64, 5-17.

Bustos, H.G., \& Gómez, M.G. (2018). Digital competence in teaching high school as a means of Innovation Educative. Journal of Educational Research, 26, 66-86.

Cabero, J., \& Román, P. (2006). E-activities: a basic reference for Internet training. Editorial MAD. ISBN: 84-665-4768-1, 11-22. Retrieved from https://dialnet.unirioja.es/servlet/libro?codigo=10840

Cabero, J. (2015). Reflexiones educativas sobre las tecnologías de la Información y la Comunicación (TIC). Technology, Science and Education. Revista de carácter científico multidisciplinar, 1, 19-27.

Carrasco, A., Donoso, J.A., Duarte-Atoche, T., Hernandez, J.J., \& Lopez, R. (2015). Design and validation of a questionnaire that measures the perceived effectiveness of using methodologies of active participation (Cempa). The case of project-based learning (ABPrj) in the teaching of accounting. Innovating, 25 (58), 143-158.

Fernandez-Cabezas, M. (2017). Project-based learning at university level: an experience of methodological innovation in education. International Journal of Developmental and Educational Psychology, Monograph, 1, №. 1, 269-278.

García-Varcálcel, A. \& Basilotta, V. (2017). Project-based learning (PBL): assessment from the perspective of primary school students. Journal of Educational Research, 35 (1), 113-131.

Hernandez, M. (2016). Evaluating Project-Based Learning. Recovered, http://www.edutopia.org/blog/evaluating-pblmichael-hernandez

Organic Law 8/2013, of 9 December, for improving educational quality. Official Gazette, December 10, 2013, nº 295

Marquès, P. (2012). Impact of ICT in Education: Functions and Limitations. Journal 3ciencias, 4, 1-15. Retrieved from https:/www.3ciencias.com/wp-content/uploads/2013/01/impacto-de-las-tic.pdf

Prendes, M.P., Castañeda, L. \& Gutiérrez, I. (2010). Skills for using ICT future teachers. Communicating Journal, V. XVIII, No. 35, 175-182.

Royal Decree 126/2014 of 28 February, the core curriculum of primary education is established. Official Gazette, March 1, 2014, $\mathrm{n}^{\circ} .52$

Salinas, J. (2008). educational innovation and ICT use. (UI of Andalusia, Ed.). Seville. ISBN: 978-84-7993-055-4. Retrieved from https://dspace.unia.es/bitstream/handle/10334/2524/innovacioneduc2008.pdf?sequence=1

Thomas, J. (2000). A review of research on project-based learning. Recovered from http://www.bobpearlman.org/BestPractices/PBL_Research.pdf 